\title{
Angklung Biomimicry Exploration
}

\author{
Bismo Jelantik Joyodiharjo ${ }^{1}$, Yasraf Amir Piliang ${ }^{2}$, and Dwinita Larasati ${ }^{3}$ \\ ${ }^{123}$ Institut Teknologi Bandung, Indonesia \\ ${ }^{1}$ bismojo@itb.ac.id ${ }^{2}$ ya piliang@yahoo.com ${ }^{3}$ titalarasati@gmail.com
}

\begin{abstract}
Nature friendly myths and traditional culture in some parts of Indonesia uses local wisdom for its agricultural activities. Ritual of Angklung (idiophone instrument made of bamboo tubes attached to a frame) playing was used during seeding, maintaining and harvesting of rice plant in order to receive spiritual blessing from Dewi Sri (goddess of fertility). There are patterns and strategies of traditional Angklung in repelling pest and fertilization of rice field. Hollow sections in bamboo tubes act as resonant chambers that produce frequencies which animals and plants respond. Altering the design of the diameter and length of the resonant chambers produces different frequencies. The main aim of this exploration is to design a modular Angklung that the Frequencies of the prototypes can be compared to animal and plant response in rice fields. With modular system, the tubes can be changed and adjusted with precice and repeated experiments. The method used is Additive Manufacturing / 3D printing. It is used not to change but to enhance the local wisdom tradition in explorative design of sustainable product. With this method, characteristics of traditional Angklung design can be maintained while transforming the material and design. The implication is by using natural method to repel pest and enhance growth of plants, we can reduce using chemicals that have harmful impacts on nature, including humans themselves. The main emphasis is sustainability.
\end{abstract}

Keywords: Additive Manufacturing, Angklung, Biomimicry, Exploration, Sustainability

\section{INTRODUCTION}

Local wisdoms are used widely as traditional culture in Indonesia. With approach to respect nature, specifically in agriculture routine, there are rituals of blessings and worship. Dewi Sri (Nyai Sri Pohaci) is mythically known as the fertility goddess. Her presence is appreciated by conducting ceremonies with sound of rattling bamboo tubes, currently known as Angklung. These artefacts have long agricultural history before transforming into an idiophone musical instrument. Biomimicry approach [1] can be used for examining Angklung sound, used as pattern that the animal responds to certain frequencies of vibrations, and the function is to repell pest or enhance the growth of the plant. These sound spectrums produced by rattling resonant bamboo tubes can be measured scientifically. 


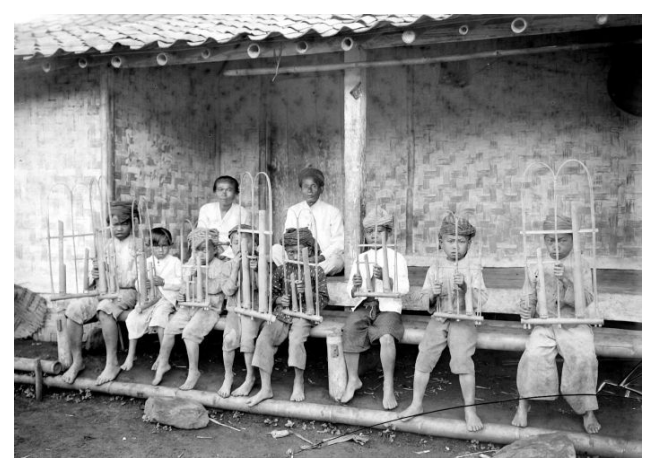

Fig 1. Young Angklung players, circa 1918. (Source: wereldculturen, n.d)

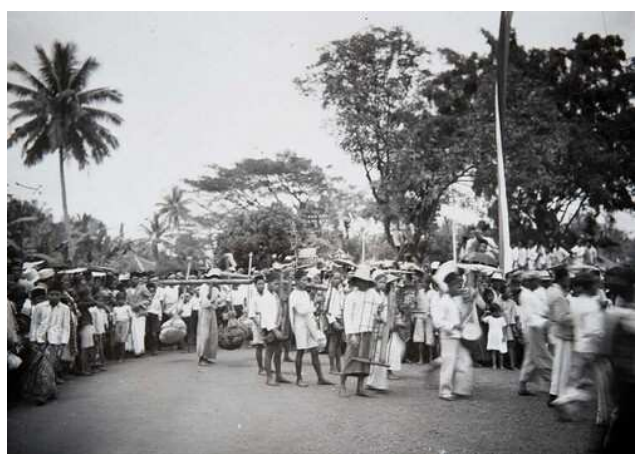

Fig 2. Music during the rice harvest in honor of the rice goddess. (Source: Bley, G. F. J. fotograaf, wereldculturen, 1925-

Myth and folklore about Angklung have existed since the 7th century. Angklung is originated and has existed before the first Hindu kingdom in West Java [2]. One of the oldest Angklungs (believed to be more than 600 years old) can be found in Bungko village, Cirebon, West Java and was used as missionary endeavor of Islam religion. Later, Angklung was spread to other places in Indonesia, such South Sumatra, Kalimantan, Lampung, Central and East Java.

Since 2010, Angklung is recognized by UNESCO as Indonesia's Intangible Cultural Heritage of Humanity in form of a musical instrument [3] but the potential of Angklung's agricultural function has not yet explored. Traditional method of Angklung playing has many advantages in repelling pests compared to the use of toxic pesticides. Designer and researcher have the responsibility to explore, enhance, expose and promote the Angklung [4].

Angklung is also listed in dictionary of the Sunda language of Java [5] and the activities involved angklung playing in west java are captured in some photographs, including the artefact (figure 1) and harvest festival in honor of rice goddess (figure 2). Before it was known as an idiophone musical instrument, Angklung has agricultural and spiritual meanings. There are two possible functions of angklung vibration in agricultural environment, as pest repellent (animal response) and as plant growth enhancer (plant response).

Ultrasound frequency, mostly beyond what human ear can detect, actively used in animal world. Sensitive responses of those sound by animal, connected to survival, reproduction and identification activities. Leaf Cricket (Copiphora Gorgonensis) can track source's position accurately by using acoustic trachea chamber at sides of their chest, slowing down soundwave movement into the eardrum beneath their knees. By comparing the sound waves delay, crickets can identify the exact distance and position of the source. Frequencies for rice plant pests are 3$5 \mathrm{kHz}$ (birds) and $38-44 \mathrm{kHz}$ (fleas).

Plant responses has been investigated and documented since the $20^{\text {th }}$ century by one of the pioneers, Jagadis Chunder Bose. He studied the behaviour of plants in response to mechanical, temperature, chemical, vibrations, and other stimulis [6]. In recent years, plant acoustic frequency technology (PAFT) have been applied and studied. It is a system to stimulate the opening of stomata by sound waves, and simultaneously apply liquid nutrients into the leafs. It has been found that different frequencies with levels of sound pressure, source distance and exposure periods influence the growth rate of plants. Sound waves within certain experiment paramaters significantly increase yield of vegetables up to $37.1 \%$ (cucumber), strengthen plant's 
immune system and reduce blight of rice by $50 \%$ [7]. Use of square waves instead of sinus was also performed in other experiment with increase in height, leaf area, stomatal opening, chlorophyll contents and weight of Mustard Pakcoy plant [8]. Other experiments involve playing music instead of fixed sound wave frequencies and observed plant growth irrespective ot the music genre [9].

Angklung was traditionally played during the planting and harvesting of the rice plant, and the effects of the sound waves during different growth stages have also been studied. Germination index, stem height, root system activity of paddy rice seeds were significantly increased at sound frequency of $0.4 \mathrm{kHz}$ and SPL of $106 \mathrm{~dB}$. Conversely, the sound waves inhibits the growth of paddy rice seeds when it exceeded $4 \mathrm{kHz}$ or $111 \mathrm{~dB}$ [10].

\section{METHOD}

The basis of this project is experimentation with emphasis of traditional artefact derived from nature and agricultural use, inspired by local wisdom and sustainable approach. Physical properties of Angklung Gubrag, which is still preserved as a ceremonial tool to enhance fertility of the rice plant, need to be confirmed by scientific measures. The spectrum waves of the sound produced can be compared to the spectrum that animal can respond, in this case ultrasound. It is very time consuming and not feasible to make prototypes of testing samples with traditional methods, as it requires special skills of Angklung maker. In addition, the most suitable materials used are also hard to find (black bamboo) and too precious to be used as disposable testing equipment. Rapid prototyping is applied form the beginning of the process to the end, with sustainability, usability, ergonomic, modularity and precision aspects for a functional product

With the Additive manufacturing method, it is possible to produce prototypes with void chambers both in structure and body. Instead of making holes from solid parts with mechanical process that use a lot of energy, time and also produce waste material, the holes and hollow sections can be made precisely from the beginning of the production process. Use of 3D design reduces the effort and time in making modular Angklung prototypes for experiment purposes compared to original bamboo tubes.

Hot bed temperature is between 45-55 C and Hot end nozzle is between 190-210 C, and after cooling down the parts can be removed from the base and on to the next process: assembly. There is no post processing needed after printing the parts. Normal printing time for part A (Frame) and B (Base) is about 2 hours. The resonant tubes take longer, about 3 and 5 hours each. Compared to original bamboo, the manufacturing time is much quicker and suits the requirement for experimentation purposes.

\section{RESULT AND DISCUSSION}

From the ground up, the creation process of the modular Angklung is based from 3D design. With digital modeling and manufacturing, form dimensions can be produced with precision, repeatedly. With just one base and main frame, samples of different tubes thickness, length and material density can be mounted. With 3D printing software, the infill is set in $20 \%$ minimum to maximum of $100 \%$. The void and cavities of natural bamboo is thicker at the outside, can be replicated (although not exactly the same) in the 3D printed sample.

As designed, the samples are able to be printed without support materials. This method helps reduce time, material and failure risks during printing process and the removal of the excess materials. The less infill, more efficient material used and quicker printing process time needed [11]. The infill can be set in geometrical form, and for this sample, honeycomb is selected for 
efficiency. Biomimicry method in taxonomy is used for finding the most efficient form, and we can learn from nature, in this case, bees that use hexagonal pattern for strength ratio versus weight and material use.

Morphologically the modular Angklung prototype is based of form follows function. The Struss section of the middle frame is conventional efficient design and similar to how nature creates form [12]. Just like a grebe bird with long neck and short tail, the middle part is counterbalanced crane and tower.

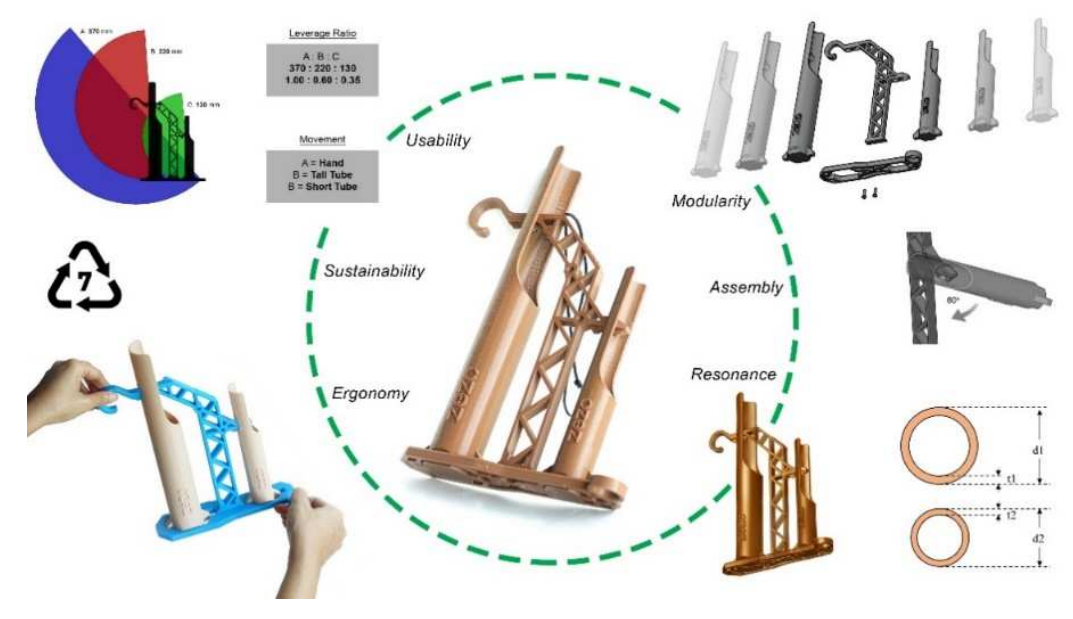

Fig 3. Circle of Angklung 3D design aspects.

(Source: Joyodiharjo, B.J., 2019)

Ergonomically, the product has to conform to basic safety and usability during operation. As ambidextrous instrument, this Angklung has two physical handles. The upper handle is an open $24 \mathrm{~mm}$ ring that can be used with just left thumb or both thumb and index finger, as a pivot point for Angklung movement. Lower handle is used to move the Angklung in horizontal rocking direction to make the rattling sound, hence the location of the $18 \mathrm{~mm}$ hole with smooth taper can be comfortably pinched with right hand. The locations of those two handles can be further optimized to make the most efficient rattling sound that caused by the impacts of the tubes into the base.

PLA (Polylactic Acid) is one of biopolymers used as filament material in FDM printing process. As bioplastic, PLA is biodegradable and more environmentally friendly compared to ABS, Nylon etc. The lower melting point of 1800 Celsius also helps with energy usage during long printing process. PLA is available in many colors, and also so many producers, some even mixed real wood with PLA and some are recycled. Further development of additive materials for $3 \mathrm{D}$ printing is possible with other more biodegradable biopolymers produced by living organism with lower melting temperature.

The leverage ratio of the handles versus the distance between the tubes to the base can be calculated and designed. Modular concept also resulted that the leverage ratio can be changed with just modifying the base or the frame, without need to change the tubes. This concept helps with efficient use of materials and also the variable requirements during experiments. Other ergonomic considerations are during assembly and maintenance. The product can be disassembled with just two M3 bolts, replace the tubes with very simple steps and physical 
upper mount that locks in place. There is triangular form of male and female joints that can be disengaged just by simply rotate the resonant tubes.

Modularity is one of main constraints in this design. As one of experimentation tools in research dissertation, the resonant tubes have to be created, tuned, changed quickly and easily without changing other parameters. With 3D printing, the variations of the tubes can be precisely fabricated with different thickness, length, proportion and material. Modularity is built-in the design as a main feature. With just 2 bolts, the product can be disassembled, tubes can be changed, and put back together easily.

The assembly of the modular Angklung can be performed with hand and 1 tool: $2 \mathrm{~mm}$ hex screwdriver. It is also possible to use Philips bolts and driver, but in this design the hex is selected due to stainless steel material which is more durable and rust-free. To prevent stripping of the treads at the main frame, the bolts should not be over-tightened during assembly. With correct torque, the 3D Angklung can be disassembled many times, and designed with long treads area to improve the durability.

The design of this modular Angklung uses zero support material. All the parts can be printed cleanly without any support and resulted in more efficient energy, material and time used to print. This concept is in harmony of the sustainability aspect of the biomimicry methodology.

Table 1. Specification of Product Samples

\begin{tabular}{ccccc} 
Sample & A & B & C & D \\
\hline Material & Bamboo & PLA wooden & PLA wooden & PLA wooden \\
\hline $\mathbf{d 1} \mathbf{( m m )}$ & 40.2 & 40.0 & 40.0 & 40.0 \\
\hline $\mathbf{d 2}(\mathbf{m m})$ & 28.1 & 28.0 & 28.0 & 28.0 \\
\hline $\mathbf{t 1}(\mathbf{m m})$ & 4.0 & 3.0 & 2.5 & 2.0 \\
\hline $\mathbf{t 2}(\mathbf{m m})$ & 3.7 & 2.5 & 2.0 & 1.7
\end{tabular}

Table 2. Fast Fourier Transform Plot Results

\begin{tabular}{ccccc} 
PLOT FFT & A1 & B1 & C1 & D1 \\
\hline Peak (Hz) & 1214 & 1583 & 1672 & 0468 \\
\hline Peak (dB) & -21 & -34 & -32 & -23
\end{tabular}

The resonant tubes are made with several variations of dimensions (table 1) for experimentation purpose. Sound characteristics (table 2), are not discussed in this article but the modularity is one of the main design concepts. The biomimicry methodology of Angklung sound to repel pest and fertilize plant can be measured with spectrum analyzed in further experiments. Variations and tuning of the sound are needed later in the research process.

\section{CONCLUSION}

Past, present and future of art and design is always evolving. Industrial revolution 4.0 technology such as Additive Manufacturing or 3D printing is used not to change but to enhance the local wisdom tradition in explorative design of traditional heritage Angklung idiophone. Recognition of earth-friendly local wisdom and exploration of this heritage traditional product can hopefully make a positive impact in food security, nature preservation and climate change awareness. Indirect impact involved is the exploration of traditional Angklung, but not as musical instrument, but as functional product with biomimicry approach of agricultural pest repellent. This approach is based on local wisdom of Dewi Sri Pohaci as mythical origin of rice plant, symbol of fertility and prosperity. 
With method of rapid prototyping, this project of design and art finds balance within aspects of modularity, ergonomic usability, repeatability, precision, ease of production and efficiency. Based on local wisdom in agricultural tradition, there are biomimicry function and pattern that can be emulated with respect of nature and sustainability. The results are a functional product that is modular for experimentation of animal response of sound in biomimicry of natural pest repellent or plant grow enhancer in small scale agricultural purpose. The final result is a design of modular Angklung that is suitable for exploration and experimentation of animal and plant responses to the sound wave produced.

\section{REFERENCES}

[1] J. M. Benyus, Biomimicry Innovation Inspired by Nature, New York: HarperCollins Publishers Inc, 2002.

[2] N. Cahyadi, "Angklung: Alat Musik Tradisional Ini Terbuat Dari Tabung-Tabung Bambu," 1312 2018. [Online]. Available: http://disdik.purwakartakab.go.id/Angklung. [Accessed 3012 2019].

[3] Rosyadi, "Angklung, dari Angklung Tradisional ke Angklung Modern," Balai Pelestarian Sejarah dan Nilai Tradisional Bandung, Bandung, 2012.

[4] B. Sugiharto, Interviewee, SD7004 Filsafat Kebudayaan. [Interview]. 15102018.

[5] J. Rigg, A Dictionary of the Sunda Language of Java, Batavia: Lange and Co., 1862.

[6] J. C. Bose, Plant Response as a means of Physiological Investigation, London, New York and Bombay: Longmans, Green and Co., 1906.

[7] Reda Hassanien, Emam Hassanien, Tian zhen HOU, Yu feng LI, Baoming Li, "Advances in Effects of Sound Waves on Plants," Journal of Integrative Agriculture, vol. 13, no. 2, p. 335-348, 2014.

[8] Zakariya, F. H., Rivai, M., Aini, N., "Effect of Automatic Plant Acoustic Frequency Technology (PAFT) on Mustard Pakcoy (Brassica rapa var. parachinensis) Plant Using Temperature and Humidity Parameters," International Seminar on Intelligent Technology and Its Applications (ISITIA), 2017.

[9] Chowdhury, A. R. and Gupta, A., "Effect of Music on Plants - An Overview," International Journal of Integrative Sciences, Innovation and Technology (IJIIT), vol. 6, no. 4 , p. $30-34,2015$.

[10] Wang, B. C., Chen, X., Wang Z., Fu Q. Z., Zhou H., Ran L., "Biological effect of sound field stimulation on paddy rice seeds," Colloids and Surfaces (B: Biointerfaces), vol. 32, pp. 29-34, 2003.

[11] Das, P., Chandran, R., Samant, R., Anand, S., "Optimum Part Build Orientation in Additive Manufacturing for Minimizing Part Errors and Support Structures," Procedia Manufacturing, vol. 1, p. 343-354, 2003.

[12] C. Williams, Origins of Form, the Shape of Natural and Man-made Things, Lanham, New York, Boulder, Toronto, Plymouth: Taylor Trade Publishing, 2013. 